\title{
Influence of Grinding Conditions and Tilting the Spindle on the Spindle Load when a 5-Axis Grinder is Used
}

Jindřich Farský, Miroslav Zetek, Tomáš Bakša, Pavel Adámek

Regional Technological Institute, University of West Bohemia - Faculty of Mechanical Engineering, Univerzitní 8, Pilsen 306 14, Czech Republic.E-mail: farskyj@rti.zcu.cz,mzetek@rti.zcu.cz,baksa@rti.zcu.cz, adamek@rti.zcu.cz

This article deals with the influence of grinding conditions and tilting the spindle on changes in the spindle load when grinding tool steel on a 5-axis tool grinding machine. The experiment was designed to investigate any changes in cutting speed, feed rate or tilting of the spindle. The size of the load is very important, because the load can influence the tool life, the life of the machine components, quality of the surfaces and dimensional accuracy of the components. A medical femoral knee replacement was selected as the semi-finished component for the experiment, as its surface is a good representative of a complex-shaped surface. This article is limited only to the grinding of maraging steel MS1 with a CBN grinding wheel. The second part of this article is focused on the experiment where the spindle load is evaluated and the results of the experiments are compared.

Keywords: Grinding conditions; Tilting the spindle; Spindle load; Grinding; 5-axis; Maraging Steel

\section{Introduction}

During grinding, the size of the grinding force is a decisive factor influencing the surface quality, accuracy, shape, durability of the grinding wheel, amount of wear on the grinding wheel and load and durability of the components in the machine. [1] The grinding conditions can influence the change of the size of the grinding force, which affects all these variables. Therefore the correct settings for the grinding conditions are very important,

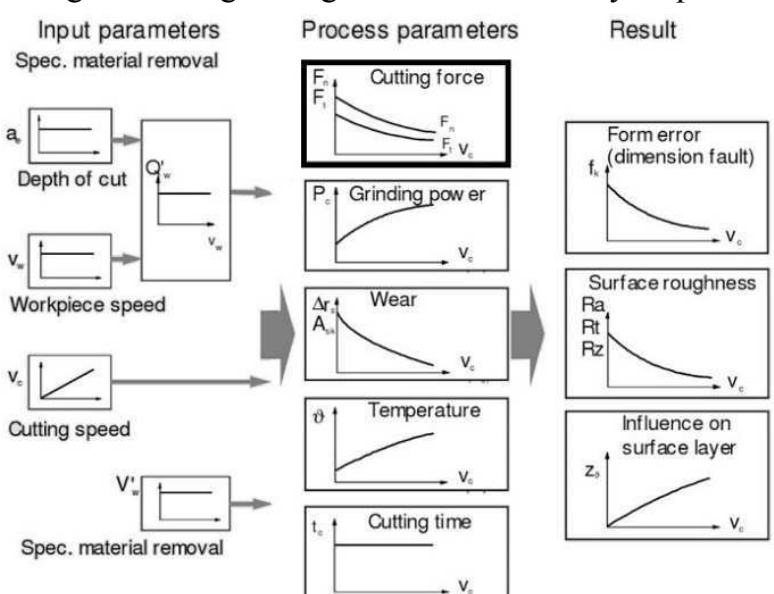

Fig. 1 Influence of grinding conditions on grinding force with results [5] and when they are set correctly it is possible to achieve more efficient grinding with lower grinding forces., [2], [3], [4] This means that if the grinding speed is increased, the grinding force will decrease. But if the feed rate of the workpiece is increased, or the amount of material taken is increased, then the grinding force also increases. This is also described in [5] and articles [1], [2], [3], [6]. The influence of the grinding conditions on the grinding forces is shown in Fig. 1.

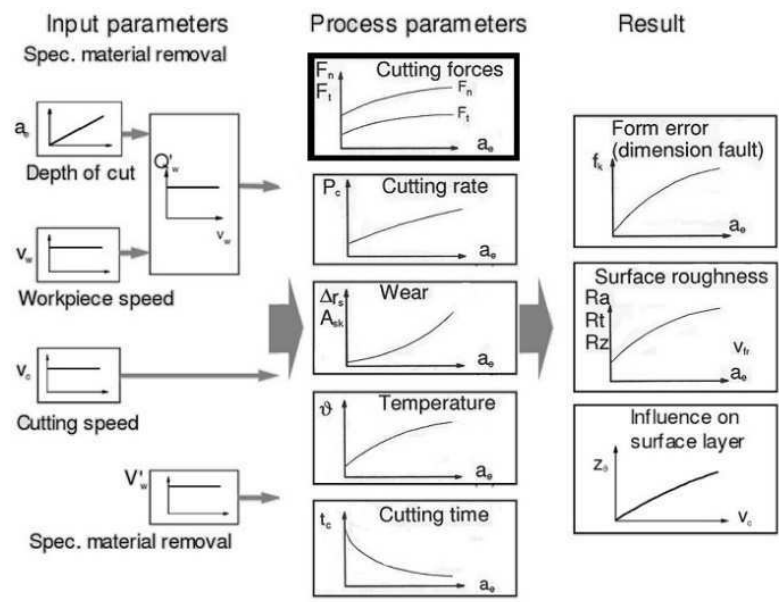

The figure shows that as well as influencing the grinding forces, grinding conditions also influence surface quality, the wear of the grinding wheel, the temperature of grinding, and so on. Changes to some grinding parameters have a positive influence on the results of grinding, which include the size of the grinding force which affects the size of wear, but also the surface roughness. Therefore this article only focuses on the grinding forces because as already mentioned, the size of the grinding forces is very important because they have an impact on the size of the wear of the grinding wheel and it can be assumed, that if the grinding forces increase, then the wear of the grinding wheel will also increase. Also, with increasing grinding forces and wear of the grinding wheel it is very probable that surface roughness and accuracy of dimensions will begin to worsen, [7], [8], [9]. Of course this depends on the composition of the grinding wheel and what type of material is used for the semi-finished product. For this work a CBN grinding wheel was selected with a radius shaped grinding part and its basic parameters are shown in Tab. 1.

Tab. 1 Specification of the used grinding wheel

$\begin{array}{lcccc}\text { Name } & \text { Shape } & \text { Dimension D-T-H metric } & \text { Specification } & \left.\text { Maximum grinding speed [m.s } \text { S }^{-1}\right] \\ \text { Grinding wheel } & \text { 1FF1 } & 100 \times 6 \times 20 & \text { B } 64 \text { C } 75 \mathrm{~B} 54 & 63\end{array}$


Maraging steel MS1 was used for the semi-finished product, a femoral knee component (Fig. 2), because this work is focused on the grinding of complex-shaped components.

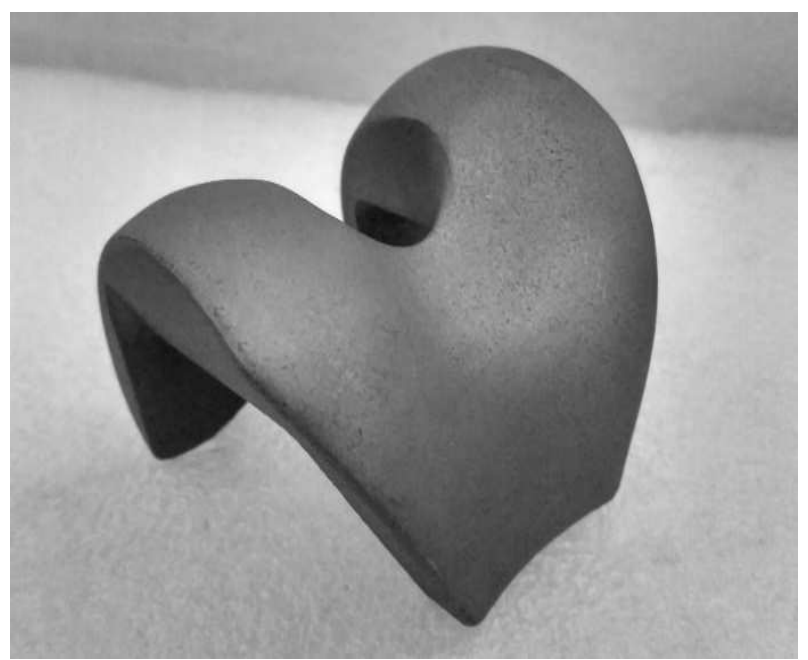

Fig. 2 Femoral knee component after 3D printing

\section{Experiment}

This experiment focuses on the spindle load, and directly on the size of the grinding forces with changing grinding conditions and tilting of the spindle. For this, it was necessary to design an experiment which contained certain variables which influence the size of the spindle load. We selected the grinding speed $v_{c}$, feed rate $v_{f}$, axial feed $a_{p}$, depth of cut $a_{e}$, and the tilt of the spindle in degrees. The sizes of individual variables are shown in Tab. 2 . The values of variables were selected on the basis of a literature search, grinding machine options, grinding wheel options and the technology of the grinding used. The grinding speed was limited by the maximum revolutions on the spindle of $10000 \mathrm{rpm}$. The axial feed rate was calculated from the size of the maximum scallop height, because the CAD/CAM software used for this only allows the setup of the maximum scallop height, but not axial feed. The equation for calculating the axial feed from the maximum scallop height is

$$
\begin{aligned}
& a_{p}=2 \cdot \sqrt{R^{2}-(R-S C)^{2}} \\
& a_{p} \ldots \text { axial feed }[\mathrm{mm}] \\
& \boldsymbol{R} \ldots \text { radius of grinding part of shape } 1 \mathrm{FF} 1[\mathrm{~m} \\
& \text { sc... maximum scallop height }[\mathrm{mm}]
\end{aligned}
$$

\begin{tabular}{|c|c|c|c|c|c|}
\hline & $v_{c}\left[m \cdot s^{-1}\right]$ & $v_{f}\left[m m \cdot s^{-1}\right]$ & $a_{p}[\mathrm{~mm}]$ & $a_{e}[\mathrm{~mm}]$ & Tilt of the spindle $\left[{ }^{\circ}\right]$ \\
\hline 01 & 30 & 150 & 0.346 & 0.05 & 0 and 30 \\
\hline 02 & 30 & 200 & 0.346 & 0.05 & 0 and 30 \\
\hline 03 & 30 & 150 & 0.155 & 0.05 & 0 and 30 \\
\hline 04 & 30 & 200 & 0.155 & 0.05 & 0 and 30 \\
\hline 05 & 40 & 150 & 0.346 & 0.05 & 0 and 30 \\
\hline 06 & 40 & 200 & 0.346 & 0.05 & 0 and 30 \\
\hline 07 & 40 & 150 & 0.155 & 0.05 & 0 and 30 \\
\hline 08 & 40 & 200 & 0.155 & 0.05 & 0 and 30 \\
\hline
\end{tabular}

Tab. 2 Variables of experiment

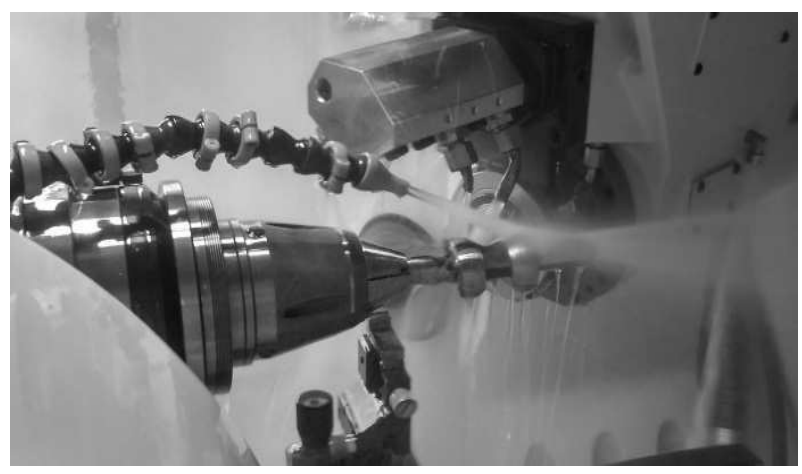

Fig. 3 The femoral knee component clamped in the grinder

As already mentioned, the experiment was focused on grinding complex-shaped components, and for this reason a femoral knee component was selected. Its outer surface was selected for experimental grinding. The experiment was done on an ANCA MX7 tool grinder with a CBN grinding wheel which has $1 \mathrm{FF} 1$ shape. This grinding wheel was used for grinding the surface with layers of thickness $0.05 \mathrm{~mm}$ which copies the shape of the knee. The grinding was divided into two parts. In the first part grinding was without tilting the spindle and in the second part grinding was with tilting the spindle, because it was also necessary to verify the influence of the tilt of the spindle on the grinding force. Because the clamp system on the grinder only allowed the clamping of cylindrical components, it was necessary to design a clamping jig, because the shape of the component does not allow it to be clamped on the machine. Fig. 3shows the clamp with the femoral knee component which was clamped in the grinder.

\section{Discussion of results}

As mentioned in the introduction, this work deals with the influence of grinding conditions and tilting the spindle on the spindle load. The spindle load was determined from the electrical power which flows directly into the spindle electromotor. Results are recorded in graphs as percentage values of the total spindle performance which is $20 \mathrm{~kW}$. One of these graphs is shown in Fig. 4 where the change in percentage of the spindle load during grinding is plotted. The size of the resultant force for each experiment is calculated from the values which are described here. The equation for calculating the resultant forces is 


$$
P=M \cdot \omega ; M=F \cdot r ; \omega=2 \cdot \pi \cdot n=>F=\frac{P \cdot p_{p}}{2 \cdot 100 \cdot \pi \cdot n \cdot r}[N]
$$

Where:

$\begin{array}{llll}\mathrm{P} & \ldots & \text { Spindle performance } & {[\mathrm{W}]} \\ \mathrm{p}_{\mathrm{p}} & \ldots & \text { Percentage of spindle load } & {[\%]} \\ \mathrm{F} & \ldots & \text { Grinding force } & {[\mathrm{N}]} \\ \mathrm{M} & \ldots & \text { Torque } & {[\mathrm{Nm}]} \\ \mathrm{r} & \ldots & \text { Grinding wheel radius } & {[\mathrm{m}]} \\ \mathrm{n} & \ldots & \text { Revolutions } & {[\mathrm{rpm}]} \\ \omega & \ldots & \text { Angular speed } & {\left[\mathrm{rad} . \mathrm{sec}^{-1}\right]}\end{array}$

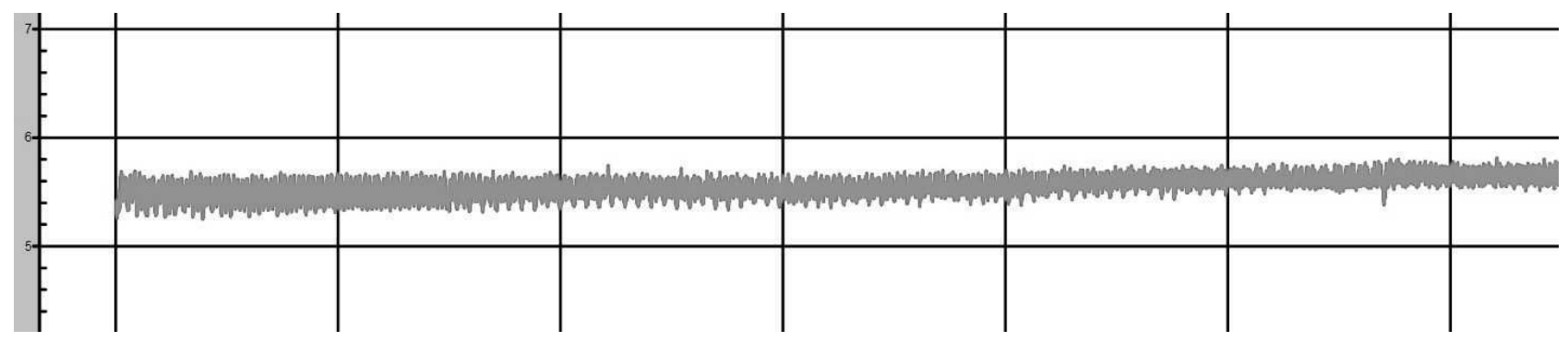

Fig. 4 Percentage of spindle load during grinding

Values of percentages of loads on the spindle were taken from the graphs which were measured during the experiments. From these values were calculated the grinding forces using equation (1). For evaluation of the load on the spindle during grinding the calculated values of forces were used. These values were recorded on the graphs and then evaluated. The influence of the grinding conditions on the grinding forces for grinding speed $v_{c}=$ $30 \mathrm{~m} \cdot \mathrm{s}^{-1}$ is shown in Graph 1 and for grinding speed $\mathrm{v}_{\mathrm{c}}=$ $40 \mathrm{~m} . \mathrm{s}^{-1}$ is shown in Graph 2. As can be seen, the curves are similar in these graphs; on the left side are values for grinding with parameters $\mathrm{a}_{\mathrm{p}}=0.346 \mathrm{~mm}$ and on the right side for $\mathrm{a}_{\mathrm{p}}=0.155 \mathrm{~mm}$. As the axial feed rate decreases, the forces increase at both grinding speeds. This is probably caused by the amount of the removed material, because when the amount of the removed material reaches a critical value, then there is an increase in the resistance of the removed material, which results in an increase in the grinding forces. Also, the increased feed rate increases the grinding forces, since there was an increase in cutting resistance.

When comparing these graphs it is also apparent that there is a change in the size of forces relative to the change in the grinding speed. As can be seen on these graphs, the values of the highest forces for grinding with a grinding speed of $40 \mathrm{~m} . \mathrm{s}^{-1}$ (marked 08 on the Graph 2) have smaller values of grinding forces than were achieved on the values of the smallest forces for grinding at speed $30 \mathrm{~m} \cdot \mathrm{s}^{-1}$ (mareked 01 on the Graph 1). The influence of the grinding speed on the size of the forces is shown in Graph 3 for better comparison of these values. When the grinding speed reaches $40 \mathrm{~m} . \mathrm{s}^{-1}$ the average value of the grinding force is lower than when the grinding speed is $30 \mathrm{~m} . \mathrm{s}^{-1}$. As seen on this graph, the tilting of the spindle also influences the grinding forces. Grinding with a tilted spindle reduces the size of the grinding forces.

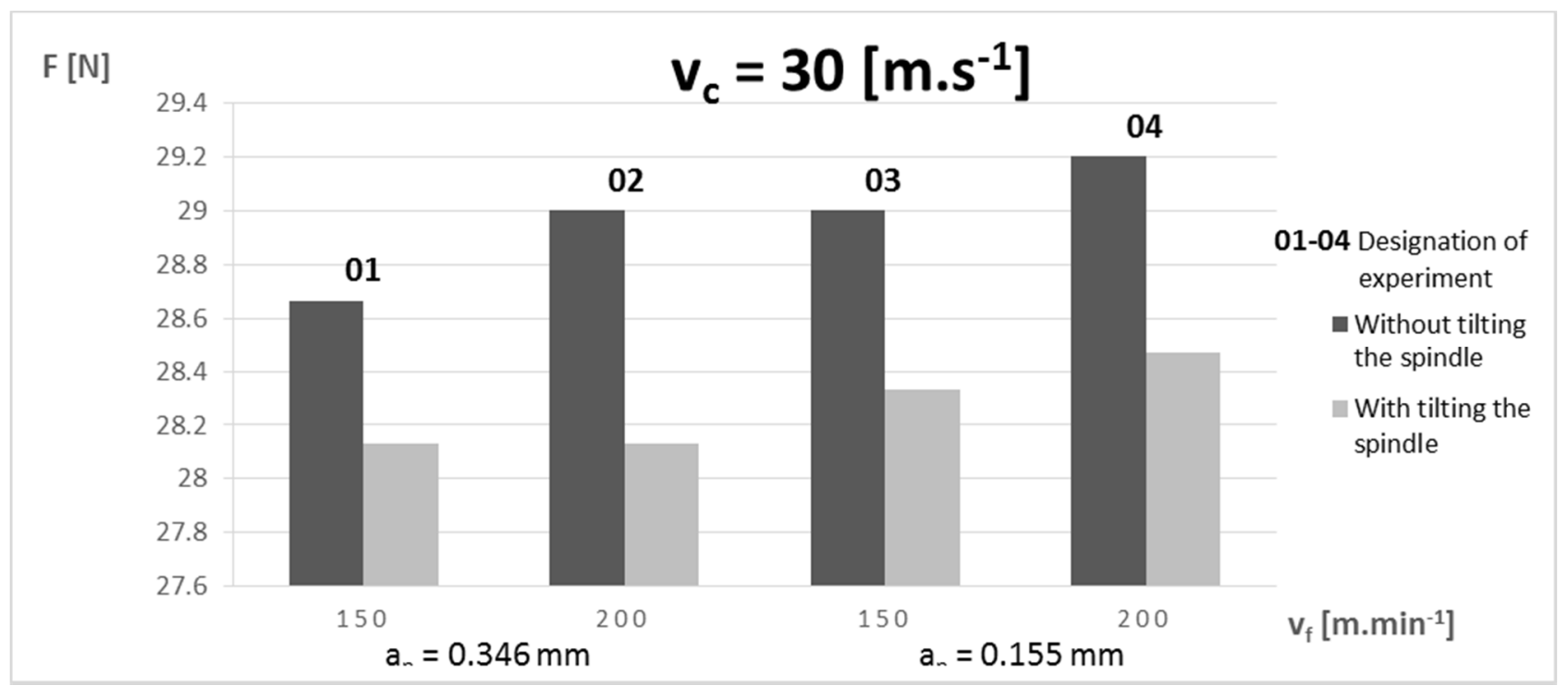

Graph 1 Influence of grinding conditions on the size of force at grinding speed $30 \mathrm{~m} . \mathrm{s}^{-1}$ 


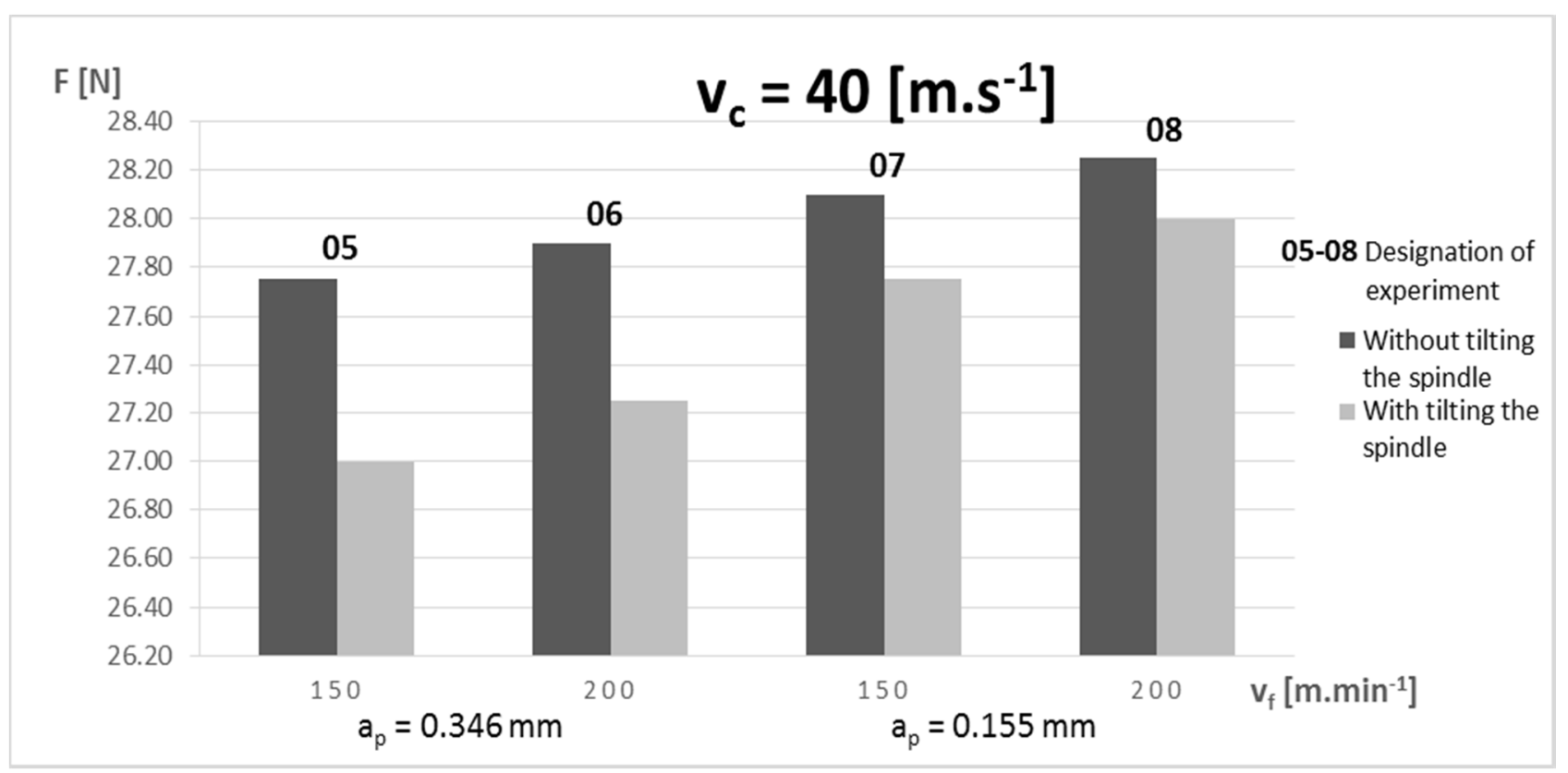

Graph 2 Influence of grinding conditions on the size of force at grinding speed $40 \mathrm{~m} \cdot \mathrm{s}^{-1}$

$\mathrm{F}[\mathrm{N}]$

29.50

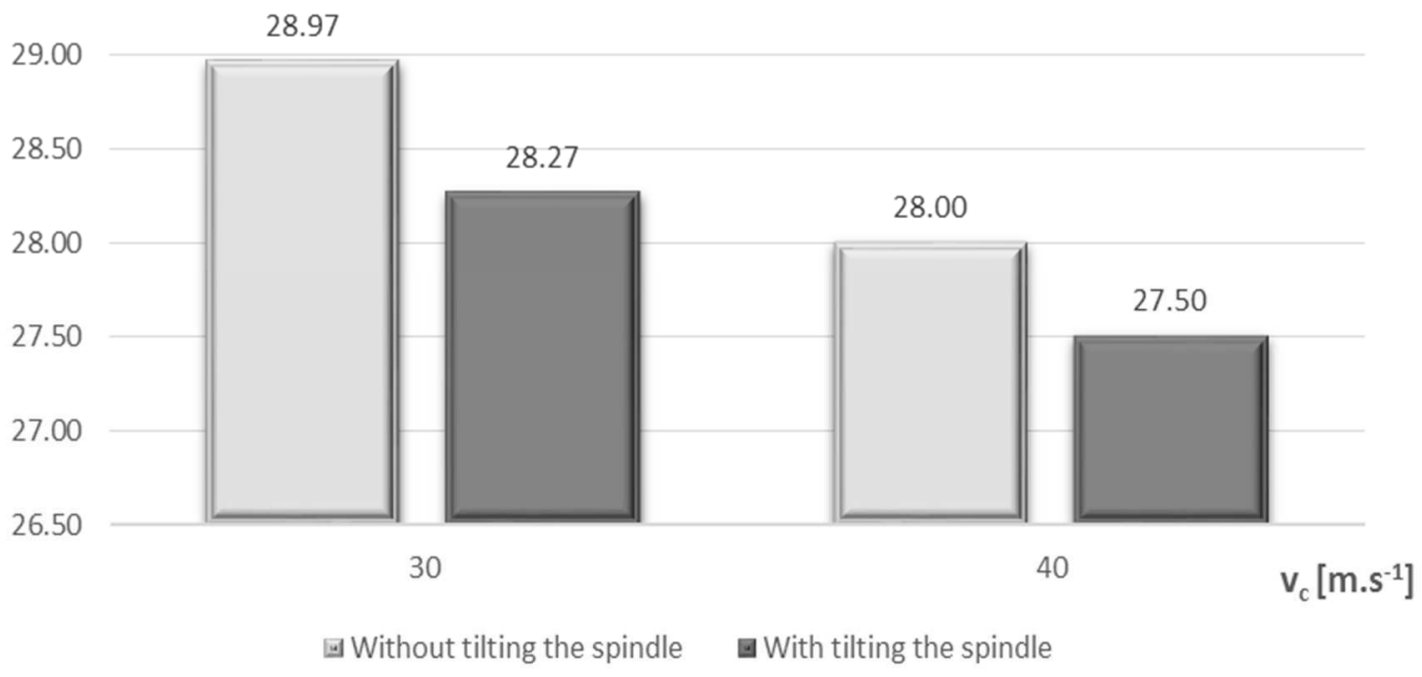

Graph 3 Influence of grinding speed and tilting the spindle on the size of grinding forces

Finally from the evaluation of the results it is necessary to find which input parameter has the biggest influence on the size of the grinding forces. Therefore it is necessary to compare the input parameters. This comparison is shown in Graph 4, which shows that the grinding speed has the biggest influence on the forces. The next biggest influence is the tilt of the spindle, then the axial feed, and last is the feed rate. Grinding speed had the opposite course to the axial feed rate and feed rate because as the grinding speed increases, the forces start to decrease. The spindle tilt has a similar course. Grinding forces were bigger if the spindle was not tilted. These changes in the influence of the grinding conditions were expected from the literature search, and these experiments confirmed this assumption.

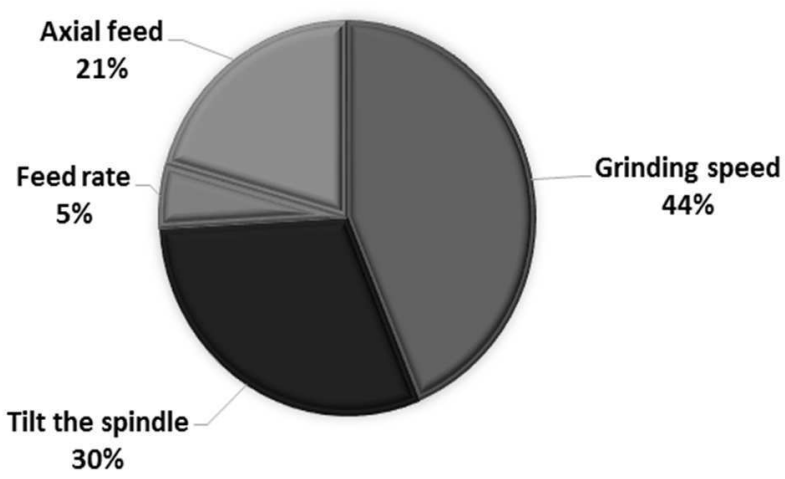

Graph 4 Comparison of influence of the input parameters 


\section{Conclusion}

This paper presents the results from an experiment which focused on the influence of grinding conditions and tilting of the spindle on the spindle load when a 5 axis grinder is used. The experimental grinding was conducted on an example of a complex shape, which was the femoral part of a medical knee component. The experimental part was focused on the measuring of the forces with different input parameters which were designed according to a literature search.

From the results it is evident that the forces can be most affected by correctly setting up the grinding speed. An increase in grinding speed decreases the size of the forces. Decreasing force has a positive effect on the quality of the surface and lifetime of the grinding wheel. An interesting change in the forces occurred when changing the axial feed parameter. Decreasing the axial feed parameter led to an increase in the size of the forces. This could have been caused by reaching a critical size of the amount of material removed. This is because after reaching this critical value, the material increases the cutting resistance and this leads to an increased size of the forces. From our results it is clear that the forces measured when grinding a complex shape show similar changes to the forces which arise when grinding a planar surface. This conclusion is based on the literature search from the articles which are listed below.

This work serves as a basis for future research which will focus on measuring the grinding forces when grinding complex-shaped surfaces. This work therefore focuses on the influence of grinding conditions and the tilt of the spindle on the spindle load. The changes of the forces which arise during grinding were evaluated and the results were compared with the literature. From the results of this work it is evident that it is necessary in the future to focus on doing more experiments which measure the forces during grinding complex-shaped surfaces, the influence of other grinding parameters and also a combination of different materials of components and grinding wheels. This paper also serves as a reference work for literature in this area of research.

\section{Acknowledgement}

This article has been prepared under project LO1502 'Development of the Regional Technological Institute' under the auspices of the National Sustainability Programme I of the Ministry of Education of the Czech Republic aimed to support research, experimental development and innovation.

\section{References}

[1] J. A. BADGER, A. A. TORRANCE (2000). A comparison of two models to predict grinding forces from wheel surface topography, Int. $J$. Mach. Tools Manuf., vol. 40, no. 8, pp. 10991120, Jun. 2000.

[2] Y. ZHANG ET AL., 'Analysis of grinding mechanics and improved predictive force model based on material-removal and plastic-stacking mechanisms, Int. J. Mach. Tools Manuf., vol. 122, pp. 81-97, Nov. 2017.

[3] C. YAO, T. WANG, W. XIAO, X. HUANG, J. REN (2014). Experimental study on grinding force and grinding temperature of Aermet 100 steel in surface grinding, J. Mater. Process. Technol., vol. 214, no. 11, pp. 2191-2199, Nov. 2014.

[4] R. LATTNER, F. HOLEŠOVSKỲ, M. NOVÁK, M. VRABEL (2016). Grinding of Titanium Alloy Ti6Al4V with Silicon Carbide Grinding Wheel, Manufacturing Technology, vol. 16, pp. 159162, Jan. 2016.

[5] F. KLOCKE (2009). Manufacturing Processes 2: Grinding, Honing, Lapping. Springer Science \& Business Media, 2009.

[6] M. NOVÁK, M. LATTNER, L. RŮŽIČKA, F. HOLEŠOVSKÝ (2010). Grinding and surface quality parameters at automotive parts machining, Manuf. Technol., vol. 10, pp. 36-38, 2010.

[7] B. DENKENA, T. GROVE, H. LUCAS (2016). Influences of grinding with Toric CBN grinding tools on surface and subsurface of 1.3344PM steel, J. Mater. Process. Technol., vol. 229, pp. 541-548, Mar. 2016.

[8] X. XIAO, K. ZHENG, W. LIAO, H. MENG (2016). Study on cutting force model in ultrasonic vibration assisted side grinding of zirconia ceramics, Int. J. Mach. Tools Manuf., vol. 104, pp. 58-67, May 2016.

M. MAREK, M. NOVÁK, K. ŠRAMHAUSER (2019). The Impact of Changes in Infeed Rate on Surface Integrity after Chrome Plate Grinding by Silicon Carbide, Manuf. Technol., vol. 19, pp. 284-291, Apr. 2019. 